\title{
IMPLEMENTASI TOTAL QUALITY SERVICE DALAM MENINGKATKAN KUALITAS PENDIDIKAN ISLAM NON FORMAL TAMAN PENDIDIKAN QUR'AN IHYAUL IMAN GADING PROBOLINGGO
}

\author{
Ulfa Qurratul Aini
}

\author{
Universitas Nurul Jadid \\ Manajemen Pendidikan Islam \\ Email: aini13225@gmail.com
}

\begin{abstract}
ABSTRAK
Pendidikan non formal adalaha pendidikan yang dipandang sebelah mata dan di anggap tidak begitu penting oleh kebanyakan masyarakat karena menurut mereka pendidikan non formal tidak begitu penting dalah dunia pekerjaan padahal tanpa mereka sadari pendidikan non formal akan selalu menunjang pendidikan formal yang pada dasarnya pendidikan formal dan pendidikan non formal berkesinambungan dan saling mendukung dalam kehidupan karena pendidikan formal dan non formal saling membutuhkan untuk membuat hidup menjadi seimbang. Dalam kehidupan sehari hari kadang kita melupakan yang namanya membaca al-qur'an karena terlalu disibukkan dengan tugas-tugas yang lain kita terlalu sibuk dengan urusan duniawi dan melupakan urusan akhirat, pada zaman yang bisa dibilang zaman now ini tidak jarang anak-anak zaman sekarang belum bisa baca tulis alqur'an kecuali mereka yang memiliki keberuntuntungan lebih untuk belajar dan menuntut ilmu di pondok pesantren,akan tetapi tidak semua dari mereka memiliki keberuntungan yang sama karena memiliki banyak faktor yang membuat mereka tidak bisa menuntut ilmu dipondok pesantren dan mereka terpaksa sekolah disekolah umum dan tinggal dirumah masing-masing, jadi karena adanya beberapa faktor itu maka muncullah pendidikan non formal yang bisa membantu mereka dalam belajar baca tulis al-qur' an yaitu TPQ (taman pendidikan qur'an) yang biasanya mereka tempuh pembelajarannya itu setelah mereka pulang dari sekolah formal mereka. Dan TPQ ini biasanya tidak berkaitan dengan pendidikan formal formal dimana mereka belajar karena TPQ ini adalah pendidikan non formal yang di dirikan oleh masyarakat sekitar unuk meningkatkan kualitas dan minat baca al-qur'an di daerah tersebut.
\end{abstract}

Kata Kunci : Implementasi, Total Quality Service, Pendidikan non formal 
A. Pendahuluan

Dalam sebuah negara pendidikan ${ }^{1}$ menjadi pacuan utama dalam memajukan negara tersebut karena majunya sebuah negara tergantung pada kemajuan sebuah pendidikan di negara itu. Pendidikan yang ada di negara indonesia ini bisa dibilang bermacam-macam karena memiliki beberapa jenis dan ciri khas tersendiri seperti madrasah, madrasah adalah pendidikan tertua di indonesia karena sebelum pendidikan umum itu maju dan berkembang pesat di indonesia madrasah telah jauh lebih maju sebelum pendidikan umum itu muncul.

Pada zaman yang sudah mulai maju ini banyak sekali anak-anak muda sekarang yang lebih tertarik untuk mempelajari pelajaran-pelajaran umum dan mengesampingkan pelajaran agamis padahal pada dasarnya semua pelajaran itu samasama dibituhkan karena mereka berkesinambungan dan dalam menuntut ilmu biasanya harus memiliki kesetaraan dalam menuntutnya, tetapi karena kurangnya pengetahuan dan banyaknya kebutuhan hidup yang harus dipenuhi maka mereka sekarang lebih memilih untuk sekolah di sekolah umum yang kata mereka lebih menjanjikan untuk mendapat pekerjaan yang akan bisa mengurangi beban hidup mereka nantinya. Meskipun sekarang ini sudah banyak pesantren-pesantren yang sudah mendirikan sekolah-sekolah umum yang dikemas kedalam lingkungan pesantren akan tetapi masih banyan anak- anak yang kurang tertarik untuk sekolah di dalam lingkungan pesantren dan lebih memilih sekolah diluar dan berangkat dari rumah masing-masing karena sudah terlena dengan lingkungan yang pergaulannya terbilang bebas.

Oleh karena itu, maka untuk mengatasi ketertinggalan mereka yang tidak mengecam ilmu agama di pondok pesantren maka masyarakat memiliki inisiatif untuk medirikan lembaga non formal untuk menanggulangi mereka yang tidak tahu baca tulis al qur'an dan sangat minim pengetahuan tentang agama. Pendidikan non-formal atau yang biasa dikenal dengan sebutan madrasah adalah pendidikan yang di dalamnya tidak mengikuti kurikulum yang ada, sebagaimana lembaga pendidikan seperti biasanya. Lembaga pendidikan non-formal ini biasa berada dalam lingkungan pedesaan atau kota-kota terpencil, seperti yang ada di desa Renteng Kec Gading Probolinggo ini lembaga pendidikan non formal yaitu taman pendidikan qur'an(TPQ) Ihyaul Iman

\footnotetext{
${ }^{1}$ Pendidikan merupakan lembaga yang dengan sengaja diselenggarakan untuk mewariskan dan mengembangkan pengetahuan, pengalaman, keteranpilan dan keahlian oleh generasi yang lebih tua kepada generasi berikutnya. Melalui pendidikan sebagian besar manusia berusaha memperbaiki tingkat kehidupan mereka. Terjadi hubungan yang kuat antara tingkat pendidikan seseorang dengan tingkat social kehidupannya. Jika pendidikan seseorang maju, tentu maju pula kehidupan, demikian pula sebaliknya.LIHAT: Sutrisno, Pendidikan Islam Yang Menghidupkan, Yogyakarta, Kota Kembang, 2008, Hal 51.
} 
yang di dirikan untuk menanggulangi anak-anak yang tidak tahu baca tulis al-qur'an dan mereka tidak mengecam ilmu pendidikan di pondok pesantren karena memiliki banyak faktor. Jadi TPQ ini adalah sebagai wadah untuk mereka mempelajari ilmu alqur'an agar mereka tidak hanya memiliki ilmu pengetahuan umum saja tetapi juga ilmu agama yang akan membuat kesempurnaan dalam menuntut ilmu.

Pendidikan non formal adalah pendidikan yang dilakukang dengan sadar dan secara teratur meskipun tidak terlaluketak sepertipendidikan formal yang biasa ada karena pendidikan non formal tidak dilakukan dalam lingkungan sekolah melainkan diluar sekolah dan sasaran pokoknya adalah masyarakat karena itu adalah lembaga non formal jadi harus dikonsep menjadi sedemikian rupa agar bersifat luwes tetapi tetep lugas namun tetep menarik minta para konsumen pendidikan. ${ }^{2}$

Pendidikan non formal atau yang biasa disebut madrasah TPQ Ihyaul Iman ini adalah sebuah lembaga pendidikan yang ada dilingkungan pegunungan pedesaan yang sengaja didirikan untuk menjadi wadah bagi mereka yang tidak tahu baca tulis alqur'an dan bisa memahami ilmu-ilmu agama lainnya.

Untuk meningkatkan kualitas pendidikan non formal TPQ biasanya ustad ustadzah yang mengajar selalu mencari metode-metode baru untuk diajarkan kepada murid-murid yang ada dan untuk menghilangkan kebosanan yang mereka alami karena biasanya dalam mempelajari ilmu-ilmu al-qur'an sering kali mengkadapi kejenuhan oleh karena itu pembina atau pun pengurus yang memiliki tanggung jawab dalam lembaga TPQ selalu memikirkan cara bagaimana membuat pelaggan tau peserta didik itu tidak bosan dalam belajar dan selalu merasa ingin belajar lagi dan lagi.

Kualitas adalah mutu yang berusaha dipenuhi oleh semua orang untuk meningkatkan suatu produk yang mereka kembangkan dan kualitas biasanya menentukan baik buruk suatu produk bisa diukur dengan kualitas yang mereka sediakan. Kualitas adalah usaha untuk memenuhi kebutuhan konsumen biasanya kualitas merupakan kondisi yang bisa berubah kadang menjadi lebih baik dan bisa juga menjadi lebih buruk itulah kualitas.

B. Pengertian Implementasi dan Total Quality Service

Dalam Oxford Advanca Learner's Distionary dikemukakan bahwa implementasi adalah "put something into effect" atau penerapan sesuatu yang memberikan efek. Implementasi adalah penerapan atau pelasanaan program yang telah

${ }^{2}$ http://eprints.uny.ac.id. Diakses pada hari Sabtu 31 Maret 2018 
dirancang sebelumnya, kemudian akan diuji dengan melaksanakan program yang telah dikembangkan dalam tahapa sebelunnya, dengan melakukan penyesuaian terhadap situasi lapangan dan karakteristik peserta didik, baik perkembangan intelektual ${ }^{3}$, emosional, serta fisiknya.

Total quality service adalah memberikan kepuasan kepada pelanggan, mewujudkan keinginan pelanggan dan selalu melakukan perbaikan yang berkesinambungan untuk mewujudkan keingina yang di inginkan oleh pelanggan dan memiliki komitmen yang sesuai untuk mengoprasionalisasikan konsep yang berfokus pada pelanggan. TQS juga adalah sistem manajemen yang melibatkan semua orang yang memiliki hak dalam mengelolanya serta metode-metode yang digunakan adalah untuk memperbaiki secara terus menerus proses organisasi agar memenuhi kebutuhan dan harapan pelanggan karena prioritas utama TQS adalah fokus pada pelanggan. ${ }^{4}$

Dalam sistem TQS ada beberapa bidang yang difokuskan di dalam sistemnya seperti:

1. Fokus Pelanggan (customer sevice), kebutuhan pelanggan adalah prioritas utama karena keinginan, kebutuhan dan harapan pelanggan adalah fokus utama sistem ini.

2. Keterlibatan Total (total involvement), harus memiliki komitmen yang total dan manajemen harus memberiakan peluang bagi karyawan untuk menunjukkan kualitas masing-masing karyawan dan menjunjung kualitas dari manajer atau atasan mereka.

3. Pengukuran, mengukur kebutuhan pelanggan baik kebutuhan internal maupun kebutuhan eksternal.

Sistem unsur-unsur pengukuran terdiri dari :

a. Melakukan penyusunan dan pengukuran proses dan hasil yang akan diperoleh.

b. melakukan identifikasi output dari proses kerja kritis dan mengukur kesesuaian dan tuntutan pelanggan.

c. Selalu melakukan evaluasi kerja dan meningkatkan kinerja karyawan.

4. Dukungan sistematis.

5. Perbaikan yang berkesinambungan, seluruh anggota yang telibat dalam organisasi harus memiliki rasa tanggung jawab terhadap organisasinya, memandang semua pekerjaan sebagai suatu proses, mengantisipasi perubahan keburuhan, keinginan

\footnotetext{
${ }^{3}$ Intelektual adalah cerdas, berakal, dan berfikir jernih berdasarkan ilmu pengetahuan. LIHAT: Kamus Besar Indonesia

${ }^{4}$ Vita Pratama Sari, Analisis Total Quality Service dengan Penerapan Quality Function Deployment, FAKULTAS EKONOMI UNIVERSITAS SEBELAS MARET SURAKARTA, 2010. 22
} 
dan harapan pelanggan, dengan senang hati menerima umpan balik tanpa rasa takut dan khawatir.

C. Pendidkan Non Formal yang Berkualitas

Pendidkan yang berkualitas akan mempengaruhi banyak hal seperti pendidikan yang maju akan membawa maju negara tersebut. Oleh karena itu, pendidikan berkualitas berupaya untuk memberdayakan peserta $\operatorname{didik}^{5}$ dan mengedepankan potensi yang dimiliki oleh peserta didik untuk menggali kecerdasan otak, kecerdasan hati, dan membekalinya dengan keterampilan-keterampilan yang dimiliki.

Pendidikan non formal yang berkualitas adalah pendidikan yang mampu menyaingi pendidikan formal dalam hal penataan atau pemberdayaan pelanggan. Pendidikan non formal yang memiliki pandangan untuk memberikan standar dalam pendidikannya seperti standar yang dimiliki oleh sekolah-sekolah formal pada umumnya akan meningkatkan kualitas yang ada pada pendidikan non formal tersebut.

Pendidikan non formal TPQ Ihyaul Iman dalam memberdayakan kualitas dan memberikan daya tarik tersendiri untuk peserta didik adalah memberikan standar-standar tertentu dalam lembaga pendidikan non formal TPQ Ihyaul Iman meskipun posisinya adalah sebagai pendidikan non formal bukan sebagai pendidikan formal tetapi lembaga TPQ Ihyaul Iman selalu memberikan kualitas yang tidak kalah baik dengan pendidikan formal dan jumlah peserta didiknya pun hampir menyamai pendidikan formal karena lembaga tersebut memberikan jaminan yang pasti terhadap pelanggan dan selalau memperbaiki fasilitas yang ada sehingga mebuat kualitasnya pun semakin terjamin.

Pendidikan non formal TPQ Ihyaul Iman selalu melakukan perbaikan perbaikan untuk mewujudkan keinginan masyarakat sekitar dan selalu meningkatkan kualitas pendidikannya. Lemabaga pendidikan non formal TPQ Ihyaul Iman memiliki visi utama adalah menjadikan santrinya menjadi pribadi yang berpegang teguh pada nilai agaman dan berpedoman pada al-qur'an dah hadist untuk kehidupan sehari-harinya. Dalam meningkatkan kualitas lembaga pendidikan non formal TPQ Ihyaul Iman para pengelola selalu mendengarkan aspirasi dari masyarakat karena adanya TPQ tersebut adalah hasil dari keluhan masyarakat yang mengatakan kecemasan mereka terhadap anak-anak mereka yang sekolah umum saja tapi tidak memiliki ketertarikan untuk mempelajari ilmu agama maka dari itu para pengelola TPQ Ihyaul Iman selalu melakukan berbagai metode

\footnotetext{
${ }^{5}$ peserta didik adalah orang-orang yang belajar di lembaga pendidikan tertentu yang menerima bimbingan pengarahan, nasihat, pembelajaran, dan berbagai hal yang berkaitan dengan proses kependidikan. LIHAT: Hasan Basri, Filsafat Pendidikan Islam. Bandung: CV PUSTAKA SETIA, 2009.
} 
mengajar untuk membuat para peserta didiknya tidak mengalami kejenuhan dan kebosanan dalam belajar seperti interaksi langsung yang dilakukan oleh ustad-ustdzah untuk memahami karakter masing-masing peserta didiknya, metode yang digunakan dalam kegiatan belajarpun bervariasi seperti metode privat, klasilak, dan BCB (belajar, cerita, bernyanyi) dan penerapan metode ini dilakukan sesuai dengan kelas masingmasing dan kelas yang ditentukan pun tergantung kemampuan dari peserta didiknya sendiri.

Dalam penerapan motede pengajaran yang dilakukan oleh pengelola TPQ Ihyaul Iman ada beberapa buku pedoman belajar yang diwajibkan oleh pengelola TPQ untuk setiap anak memilikinya dan buku pedoman itu biasanya dimiliki oleh semua peserta didik dari tinkat dasar sampai yang tertinggi dan buku pedoman tersebut memiliki beberapa tingkatan tergantung kemampuan peserta didik itu sendiri. Seperti tartila jilid 13 itu untuk tingkatak kelas ula karaena kelas ula adalah kelas terrendah yang ada di TPQ Ihyaul Iman tartila 4 untuk kelas wustho dan tartila 5-6 untuk kelas ulya yaitu tingkatan tertinggi di TPQ Ihyaul Iman. Untuk menentukan tingkatan tersebut maka peserta didik harus mempelajarinya dari awal dari tartila jilid 1 tapi setelah selesai mempelajarinya kita tidak langsung lanjut mempelajari tartila jilid 2 karena untuk lanjut mempelajari tartila jilid 2 peserta didik harus benar-benar sudah memahami tartila jilid 1 jika masih belum bisa memahaminya maka peserta didik wajib unuk mengulangnya dari awal.

TPQ Ihyaul Iman memiliki cara tersendiri untuk bisa membuat peserta didik bisa cepat memahami pelajaran yang ada dan metode-metode yang digunakan pun menyesuaikan dengan keadaan peserta didik karena jika metode yang digunakan tidak disukai oleh peserta didik maka itu bisa bemacu peserta didik untuk males belajar dan itu akan membuat motivasi belajar peserta didik berkurang. Oleh karena itu setiap pendidik yang ada harus selalu berusaha untuk membuat peserta didik nyaman dan senang dalam waktu pelajaran berlangsung karena mempelajari atau mendalami pelajaran yang membahas Al- Qur'an akan sering jenuh atau membosankan berbeda dengan mata pelajaran yang lain, sehingga tantangan yang dimiliki oleh pendidik pun lebih berat dan tanggung jawab yang di embanpun sangat berat.

Adapun waktu pelaksanaan kegiatan belajar mengajar TPQ Ihyaul Iman itu dilaksanakan pada siang hari karena TPQ Ihyaul Iman ini berada dalam lingkungan yayasan Ihyaul Iman yang mana di yayasan ini juga berdiri pendidikan formal maka TPQ Ihyaul Iman menyesuaikan dengan pendidikan formalnya agar tidak mengganggu kegiatan yang lain. Dan pendidikan non formal di yayasan Ihyaul Iman itu bukan hanya 
TPQ saja masih ada pada madin juga maka pelaksanaan KBM nya juga tiga hari dalam seminggu yaitu hari minggu, rabu, dan jum'at.

Untuk meningkatkan kualitas pendidikan non formal TPQ Ihyaul Iman menggunakan empat teknik dalam pengelolaannya yaitu :

\section{School Review}

Teknik ini menekankan kerja sama antara pengelola dengan orang tua peserta didik untuk mengevaluasi semua tentang TPQ Ihyaul Iman mulai dari layanan dan fasilitas untuk meningkatkan kualitas.

2. Benchmarking

Teknik ini merupakan suatu kegiatan untuk menetapkan standar dan tujuan yang ingin dicapai dalam periode tertentu.

3. Quality Assurance

Teknik ini untuk menentukan apakah renvana yang telah dirancang sebelumnya sesuai dan berjalan dengan lancar dengan teknik ini pula bisa diketahuai jika dalam proses berjalanya rencana yang telah dirancang itu ada masalah atau kendala yang akan menjadi hambatan untuk mencapai tujuan.

4. Quality Control

Teknik ini digunakan untuk mendeteksi apabila terjadi penyimpangan kualitas output yang tidak sesuai dengan standar.

Dalam pendidikan non formal peningkatan kualitasnya pun berbeda dengan peningkatan kualitas terhadap pendidikan formal karena pendidikan non formal mempunyai ciri yang berbeda meskipun berbeda tetapi pendidikan non formal dan pendidikan formal saling melengkapi. Ciri-ciri pendidikan non formal adalah sebagai berikut

1. Bertujuan membuat keterampilan yang langsung bisa dipergunakan. Pendidikan non formal ditekankan pada belajar yang fungsional yang memang dibutuhkan dalam kehidupan sehari-hari.

2. Berpusat pada peserta didik.

3. Waktu penyelenggaraannya relative singkatb dan tidak berkesinambungan.

4. Menggunakan kurikulum kafetaria. Kurikulum bersifat fleksibel, dapat dimusyawarohkan secara terbuka dan banyak ditentukan oleh peserta didik.

5. Menggunakan metode pembelajaran yang partisipatif. 
6. Hubungan pendidik dengan peserta didik bersifat mendatar, pendidik bukan menggurui tapi sebagai fasilitator jadi hubungaan diantara dua pihak bersifat informal dan akrab.

\section{Peran Pendidikan Non Formal Kepada Pendidikan Formal}

Masalah yang ada pada pendidikan formal atau pendidikan di sekolah menyebabkan pendidikan non formal mengambil peran untuk membantu keresahan masyarakat yang ada, untuk mengurangi masalah tersebut maka pendidikan non formal mengambil peran didalamnya untuk membantu mengurangi masalah tersebut. Peran pendidikan non formal adalah sebagai "pelengkap, penambah, dan pengganti" dengan pengerttian sebagai berikut:

1. Sebagai pelengkap pendidikan formal atau pendidikan sekolah. Pendidkan non formal berfungsi untuk melengkapi kemampuan peserta didik dengan jalan memberikan pengalaman belajar yang tidak mereka dapatkan di sekolah.

2. Sebagai penambah pendidikan formal atau sekolah. Pendidikan non formal sebagai penambah pendidikan formal bertujuan untuk menyediakan kesempatan belajar kepada peserta didik yang ingin memperdalam materi tertentu.

3. Sebagai penggainti pendidikan formal. Pendidikan non formal sebagai pengganti pendidikan formal menyediakan kesempatan belajar bagi anakanak yang ingin menembah pengentahuannya dan wawasannya.

E. Kesimpulan

Penerapan suatu program yang dirancang untuk meningkatkan kualitas lembaga TPQ non formal untuk memenuhi kebutuhan dan keinginan pelanggan. Dalam sistem total quality service ada beberapa sistem yang difokuskannya seperti, Fokus Pelanggan, Keterlinatan Total, Pengukuran, dukungan sistematis dan perbaikan yang berkesinambungan.Pendidikan non formal TPQ Ihyaul Iman selalu melakukan perbaikan perbaikan untuk mewujudkan keinginan masyarakat sekitar dan selalu meningkatkan kualitas pendidikannya.Dalam meningkatkan kualitas lembaga pendidikan non formal TPQ Ihyaul Iman para pengelola selalu mendengarkan aspirasi dari masyarakat karena adanya TPQ tersebut adalah hasil dari keluhan masyarakat yang mengatakan kecemasan mereka terhadap anak-anak mereka yang sekolah umum saja tapi tidak memiliki ketertarikan untuk mempelajari ilmu agama maka dari itu para pengelola TPQ Ihyaul Iman selalu melakukan berbagai metode mengajar untuk membuat para peserta didiknya tidak mengalami kejenuhan dan kebosanan dalam belajar seperti interaksi langsung yang 
dilakukan oleh ustad-ustdzah untuk memahami karakter masing-masing peserta didiknya.

TPQ Ihyaul Iman memiliki cara tersendiri untuk bisa membuat peserta didik bisa cepat memahami pelajaran yang ada dan metode-metode yang digunakan pun menyesuaikan dengan keadaan peserta didik karena jika metode yang digunakan tidak disukai oleh peserta didik maka itu bisa bemacu peserta didik untuk males belajar dan itu akan membuat motivasi belajar peserta didik berkurang. Oleh karena itu setiap pendidik yang ada harus selalu berusaha untuk membuat peserta didik nyaman dan senang dalam waktu pelajaran berlangsung karena mempelajari atau mendalami pelajaran yang membahas Al- Qur'an akan sering jenuh atau membosankan berbeda dengan mata pelajaran yang lain, sehingga tantangan yang dimiliki oleh pendidik pun lebih berat dan tanggung jawab yang di embanpun sangat berat.

Adapun waktu pelaksanaan kegiatan belajar mengajar TPQ Ihyaul Iman itu dilaksanakan pada siang hari karena TPQ Ihyaul Iman ini berada dalam lingkungan yayasan Ihyaul Iman yang mana di yayasan ini juga berdiri pendidikan formal maka TPQ Ihyaul Iman menyesuaikan dengan pendidikan formalnya agar tidak mengganggu kegiatan yang lain. Dan pendidikan non formal di yayasan Ihyaul Iman itu bukan hanya TPQ saja masih ada pada madin juga maka pelaksanaan KBM nya juga tiga hari dalam seminggu yaitu hari minggu, rabu, dan jum'at. 


\section{DAFTAR RUJUKAN}

Sutrisno, 2008. Pendidikan Islam Yang Menghidupkan, (Yogyakarta, Kota Kembang).

Vita Pratama Sari, Analisis Total Quality Service dengan Penerapan Quality Function Deployment,SKRIPSI FAKULTAS EKONOMI UNIVERSITAS SEBELAS MARET SURAKARTA, 2010.

Mundiri, A. (2016). THE LEADERSHIP OF HEADMASTER IN BUILDING A WORK CULTURE BASED ON PESANTREN. In International Conference on Education and Training (pp. 1-7). Malang: Faculty of Education State University of Malang.

Mundiri, A. (2017). Organizational Culture Base On Total Quality Management In Islamic Educational Institution. ADRI International Journal Of Islamic Studies and Social Sciences, 1(1), 1-11.

Mundiri, A., \& Zahra, I. (2017). Corak Representasi Identitas Ustadz dalam Proses Transmisi Pendidikan Karakter di Pesantren. Jurnal Pendidikan Islam, Vol. 2, No, 21-35.

Hasan Basri, 2009. Filsafat Pendidikan Islam, (Bandung: CV PUSTAKA SETIA). Moh. Rifa'i, 2017. Community Empowerment In Islamic Boarding School. (Probolinggo: Cv Mandiri).

Robiatul adawiyah, implikasi pendidikan non formal pada remaja. Jurnal Equilibrium Sosiologi vol IV No.2 November 2016. Diakses pada tanggal 31 Maret 2018.

Ummul Aiman Lubis, Implementasi manajemen berbasis sekolah dalam meningkatkan mutu. Jurnal Analytica Islamica vol 4 No1 2015: 167-186. Diakses pada tanggal 31 Maret 2018.

Ichwani Tri Wikanah, pengelolaan pembelajaran berbasis kualitas dilembaga kursus. Journal Of Nonformal Education vol 1 No1 2015. Diakses pada tanggal 01 April 2018. 